\title{
Qualidade de peles bovinas em frigoríficos do município de São Luís/MA: avaliação técnica e operacional do sistema de classificação brasileiro
}

Relvis Antônio Farias do Vale, Raimunda Deusilene Barreira Porto,Priscila Alencar Beserra, Amanda Taylla Lima Silva, Natalia Lustosa Cavalcante, Naylla Raquel Costa Leite Campos, Ana Karlaylle Pereira de Jesus, Danilo Cutrim Bezerra, Nancyleni Pinto Chaves Bezerra, Hamilton Pereira Santos"

Universidade Estadual do Maranhão (UEMA), São Luís, MA, Brasil

*Autor correspondente

e-mail: hpsluiza@yahoo.com.br

\section{Resumo}

O sistema de produção animal no Brasil, tipicamente extensivo e de longo prazo, expõe os bovinos por mais tempo aos elementos causadores de defeitos na pele, como os parasitas, cercas de arame farpado e prática de marcação a ferro quente fora dos locais recomendados, cujas injúrias inutilizam a parte nobre do couro, o grupon. A legislação brasileira classifica as peles bovinas em três níveis (A, B e C) conforme a quantidade e a localização dos seus defeitos (carrapato, berne cicatrizado, placa de berne, risco aberto, risco cicatrizado e marca a fogo), e indica o corredor de abate como o local onde o classificador deverá posicionar-se para proceder tal avaliação. 0 objetivo do estudo foi avaliar a viabilidade técnica e operacional do sistema de classificação de peles bovinas proposta pelo MAPA em frigoríficos do município de São Luís, Maranhão. 0 estudo foi realizado em três frigoríficos sob SIM, que recebem animais de todos os municípios maranhenses, contemplando rebanhos com diferentes idades e procedências e das raças Nelore e mestiços. Os dados foram coletados no período de setembro a dezembro de 2016 durante o abate, quando foram realizadas simulações do sistema de classificação instituído pela IN n. 12 de 2002, registrando-se os defeitos da pele passíveis de visualização a olho nu e desarmado. As peles bovinas foram avaliadas na salgadeira, pela inviabilidade operacional desta etapa ter sido realizada no corredor de abate, local designado para a classificação na legislação. A avaliação foi realizada na região dorso-lateral das peles, denominada grupon, pescoço e barriga. O número de peles classificados como " $\mathrm{A}$ " foi pequeno (2\%), uma vez que nessa classificação as peles podiam apresentar apenas carrapatos na barriga, sendo os demais defeitos não admitidos. Já na classe $B$, onde carrapatos na barriga, berne curado e risco cicatrizado fora do grupon eram admitidos, foram enquadradas 28 peles $(6,4 \%)$. 0 maior percentual $(91,60 \%)$ das peles analisadas integrou a classe C, categoria onde os defeitos são admitidos com maior flexibilidade. Quanto à viabilidade técnica do sistema de classificação, analisaram-se os defeitos e sua pertinência dentro do sistema de produção e abate de bovinos. Os defeitos 
que interferiram negativamente na qualidade das peles avaliadas em ordem decrescente de frequência foram: marcas a ferro quente $(95,24 \%)$, riscos cicatrizados $(91,40 \%)$ e abertos $(90,972 \%)$, presença de carrapatos $(88,23 \%)$ e berne $(0,23 \%)$. A mosca-dos-chifres e dermatites, apesar de não estabelecidos na legislação, mas por serem problemas comuns no Maranhão, foram avaliados e incriminados como causas de defeitos nas peles bovinas. Os resultados obtidos permitiram concluir que o sistema de classificação brasileiro precisa ser reformulado tanto do ponto de vista técnico quanto operacional para garantir a efetividade no processo de avaliação de peles e couros de bovinos. 